\title{
Analisis Kualitas Pelayanan di Program Studi Farmasi Poltekkes Kemenkes Pangkalpinang Menggunakan Metode SERVQUAL
}

\section{Analysis of Service Quality at Pharmacy Study Program Polytechnic Health Ministry of Pangkalpinang using SERVQUAL Method}

\author{
Ratih Puspita Kusumadewi Purba ${ }^{1 *}$ dan Mirnawati Zalili Sailan² \\ 1. Prodi Farmasi - Poltekkes Kemenkes Pangkalpinang, Indonesia \\ 2. Prodi Farmasi - Poltekkes Kemenkes Pangkalpinang, Indonesia \\ *ratihp.puspita@gmail.com
}

\begin{abstract}
Abstrak
Latar belakang: Kepuasan mahasiswa sebagai pelanggan lembaga pendidikan merupakan salah satu Sasaran Mutu yang harus diukur secara rutin. Analisis kualitas pelayanan dapat dilakukan dengan metode Service Quality (SERVQUAL).

Tujuan: Menganalisis kualitas pelayanan menggunakan Metode SERVQUAL melalui: 1) penetapan CSI dan 2) penentuan prioritas perbaikan menggunakan Diagram Kartesius.

Metode: Penelitian ini merupakan penelitian deskriptif dengan pendekatan cross sectional. Instrumen penelitian berupa kuesioner yang terdiri atas 5 dimensi pokok SERVQUAL, yaitu tangibles (berwujud), empathy (empati), assurance (jaminan), reliability (keandalan), dan responsiveness (daya tanggap). Data ekspektasi dan persepsi pada setiap item pernyataan digunakan untuk menetapkan CSI. Untuk mengetahui item yang perlu mendapatkan perbaikan, maka analisis dilanjutkan dengan penentuan prioritas perbaikan melalui pembuatan Diagram Kartesius. Responden adalah mahasiswa Program Studi Farmasi Poltekkes Kemenkes Pangkalpinang berjumlah 99 orang.

Hasil: Kualitas pelayanan yang ditunjukkan melalui CSI sebesar $80,34 \%$ dan berada dalam kategori Puas. Dimensi Emphaty merupakan dimensi dengan indeks kepuasan tertinggi sebesar 82,39\% dalam kategori Puas dan dimensi Tangible merupakan dimensi dengan indeks kepuasan terendah sebesar 77,93\% dalam kategori Puas. Prioritas utama perbaikan yang ditetapkan menggunakan metode Diagram Kartesius yaitu kemudahan akses layanan internet, keramahan Tenaga Kependidikan dalam melayani mahasiswa, tingkat keamanan kampus, dan kemampuan Dosen dalam menghidupkan suasana kelas.

Kesimpulan: Kualitas pelayanan terhadap mahasiswa di Program Studi Farmasi Poltekkes Kemenkes Pangkalpinang yang dinilai mahasiswa berada dalam kategori "Puas" perlu ditingkatkan melalui perbaikan sesuai prioritas utama Diagram Kartesius.
\end{abstract}

Kata kunci: Customer Satisfaction Index, Diagram Kartesius, Importance-Performance Analysis, Kepuasan, SERVQUAL

\section{Abstract}

Background: Student satisfaction as an educational institution is one of the quality objectives that should be measured on a regular basis. Service quality analysis can be done by Service Quality (SERVQUAL) method.

Objective: The research aims to analyse the quality of services using the SERVQUAL method through: 1) the determination of CSI and 2) Determination of priority improvements using the Cartesian Diagram.

Method: This research is a descriptive study with a cross sectional approach. The research instrument is a questionnaire consisting of 5 main dimensions of SERVQUAL, namely tangibles, empathy, assurance, reliability, and responsiveness. The expectation and perception Data on each item statement is used to establish CSI. To find out the items that need to be improved, the analysis 
continues with the determination of priority improvements through the creation of a Cartesian Diagram. Respondents to the study were students of the Pharmacy Study Program Polytechnic Health Ministry of Pangkalpinang amounting to 99 people.

Result: The results showed the quality of service demonstrated through CSI by $80.34 \%$ and are in the category Satisfied. The Emphaty dimension is a dimension with the highest satisfaction index of $82.39 \%$ in the Satisfied category and the Tangible dimension is the dimension with the lowest satisfaction index of $77.93 \%$ in the Satisfied category. The main priority of the improvement set using the Cartesian Diagram method is the ease of access to Internet services, the friendliness of education in serving students, the level of security of the campus, and the ability of lecturers in bringing the classroom atmosphere.

Conclusion: The quality of service to students at the Pharmacy Study Program Polytechnic Health Ministry of Pangkalpinang students who are judged to be in the category of "Satisfied" need to be improved through improvement according to the main priority of the Cartesian Diagram.

Keywords: Customer Satisfaction Index, Cartesian Diagram, Importance-Performance Analysis, Satisfaction, SERVQUAL

\section{PENDAHULUAN}

Pengelolaan mutu penyelenggaraan pendidikan merupakan tantangan penting yang dihadapi oleh Lembaga Pendidikan (sekolah, perguruan tinggi, maupun universitas). Pada saat ini dunia pendidikan dihadapkan dengan adanya model pengelolaan pendidikan berbasis industri. Pengelolaan berbasis industri menuntut adanya upaya pihak pengelola institusi pendidikan untuk meningkatkan mutu pendidikan berdasarkan manajemen perusahaan. Institusi pendidikan memposisikan diri sebagai penyedia jasa/ pelayanan (service) sesuai dengan apa yang diinginkan oleh pelanggan (customer). Pelanggan menginginkan pelayanan yang bermutu yang kemudian yang bermuara pada kepuasan yang dirasakan. Dengan demikian, dibutuhkan suatu sistem manajemen yang mampu memberdayakan institusi pendidikan agar lebih bermutu. ${ }^{(1)}$

Persaingan dalam lembaga pendidikan dalam rangka meningkatkan mutu penyelenggaraan pelayanan pendidikan sangat ketat. Salah satu tujuan peningkatan mutu pendidikan adalah untuk menghasilkan lulusan yang lebih baik. Di samping itu juga agar lembaga pendidikan mampu bertahan di tengah-tengah persaingan yang semakin ketat. Di Pangkalpinang, meskipun saat ini hanya Poltekkes Kemenkes Pangkalpinang yang memiliki Program Studi DIII Farmasi di wilayah Provinsi Kepulauan Bangka Belitung, terdapat wacana akan berdiri lembaga pendidikan baru yang memiliki program studi Farmasi. Hal tersebut perlu mendapatkan perhatian bagi Poltekkes Kemenkes Pangkalpinang untuk segera mempersiapkan diri menghadapi kompetitor dengan cara meningkatkan kualitas pelayanan pendidikan. Secara umum, baiknya kualitas pelayanan perguruan tinggi akan mempengaruhi banyak sedikitnya peminat (calon mahasiswa) yang ingin masuk ke perguruan tinggi tersebut. Kualitas pelayanan yang diberikan oleh Program Studi Farmasi Poltekkes Kemenkes Pangkalpinang dapat diketahui melalui kepuasan mahasiswa sebagai pelanggannya. Kepuasan pelanggan bergantung pada kinerja persepsi produk terhadap ekpektasi pelanggan. Jika kinerja tidak memenuhi ekpektasi, maka pelanggan merasakan ketidakpuasan. Sebaliknya jika kinerja sesuai dengan ekspektasi maka pelanggan akan merasakan kepuasan. Adapun jika kinerja melebihi ekspektasi maka pelanggan akan sangat puas. Poltekkes Kemenkes Pangkalpinang sebagai lembaga perguruan tinggi memiliki karakteristik penerima jasa yang diberikan adalah orang (mahasiswa) sehingga berdasarkan hubungan antara pemberi jasa dan penerima/pengguna jasa/pelanggan digolongkan high contact system. Pemberi jasa dan pelanggan selalu berinteraksi selama pemberian jasa berlangsung sehingga pelanggan harus menjadi bagian dari sistem tersebut. ${ }^{(2)}$ 
Kepuasan mahasiswa merupakan salah satu Sasaran Mutu yang harus diukur secara rutin. Kepuasan mahasiswa tercapai saat tidak terdapat kesenjangan antara ekspektasi dan persepsi mahasiswa terhadap layanan kemahasiswaan maupun terhadap penyelenggaraan pendidikan. Kepuasan didefinisikan sebagai perasaan senang atau kecewa sebagai hasil dari perbandingan antara prestasi atau produk yang diharapkan dan apa yang diharapkan. Untuk membedakan mutu perusahaan jasa yang dalam hal ini adalah perguruan tinggi yaitu dengan menyediakan pelayanan yang lebih baik dari pesaing-pesaingnya secara konsisten dengan cara memenuhi harapan-harapan konsumen tentang mutu pelayanan yang diinginkan. Kepuasan pelanggan terhadap pelayanan yang diperolehnya akan berpengaruh kepada pola perilaku konsumen tersebut selanjutnya. ${ }^{(3)}$

Analisis mutu pelayanan dapat dilakukan dengan metode Service Quality (SERVQUAL) yang dikembangkan oleh Parasuraman et al. ${ }^{(4)}$ Dengan metode SERVQUAL dapat ditentukan Customer Satisfaction Index (CSI) atau indeks kepuasan pelanggan yang dalam hal ini diwakili oleh mahasiswa selaku pelanggan Program Studi Farmasi Poltekkes Kemenkes Pangkalpinang. Customer Satisfaction Index merupakan indeks untuk menentukan tingkat kepuasan pelanggan secara menyeluruh dengan pendekatan yang mempertimbangkan tingkat kepentingan/ekspektasi dari atribut produk atau jasa yang diukur. ${ }^{(5)}$ Penetapan CSI dapat dilanjutkan dengan penetapan prioritas perbaikan menggunakan Importance-Performance Analysis/IPA atau biasa disebut dengan Diagram Kartesius. Penggunaan CSI dan Diagram Kartesius secara simultan merupakan metode yang tepat untuk meningkatkan kualitas pelayanan dengan tepat sasaran.

Berdasarkan uraian di atas, perlu dilakukan penelitian tentang analisis kualitas pelayanan di Program Studi Farmasi Poltekkes Kemenkes Pangkalpinang menggunakan meotde SERVQUAL.

\section{METODE}

\section{Jenis Penelitian}

Jenis penelitian merupakan penelitian deskriptif dengan pendekatan cross sectional untuk mengukur indeks kepuasan mahasiswa terhadap penyelenggaraan pendidikan di Program Studi Farmasi Poltekkes Kemenkes Pangkalpinang pada masing-masing dimensi SERVQUAL untuk kemudian dilanjutkan dengan penetapan prioritas perbaikan menggunakan metode Diagram Kartesius.

\section{Waktu dan Tempat Penelitian}

Penelitian dilakukan pada bulan April-Desember 2018 di Program Studi Farmasi Poltekkes Kemenkes Pangkalpinang.

\section{Subjek Penelitian}

Subjek penelitian adalah seluruh mahasiswa Program Studi Farmasi Poltekkes Kemenkes Pangkalpinang pada Tahun Akademik 2018/2019 sebanyak 99 orang yang terdiri atas mahasiswa tingkat I sebanyak 40 orang, mahasiswa tingkat II sebanyak 30 orang, dan mahasiswa tingkat III sebanyak 29 orang.

\section{Instrumen}

Dalam implementasi CSI disusun kuesioner yang diisi oleh pelanggan dan menghasilkan data berupa tingkat kepuasan yang dicapai. ${ }^{(6)}$ Kuesioner sebagai alat ukur penelitian disusun berdasarkan skala Likert dengan skala 1 sampai dengan 4 baik pada ekspektasi maupun persepsi. Instrumen dalam penelitian ini menggunakan kuesioner penelitian Faraby yang telah dimodifikasi. ${ }^{(7)}$ Instrumen penelitian berupa kuesioner yang terdiri atas 5 dimensi pokok SERVQUAL, yaitu tangibles (berwujud), empathy (empati), assurance (jaminan), reliability (keandalan), dan responsiveness (daya tanggap). Pada kuesioner dilakukan uji validitas dan 
reliabilitas. Uji validitas dan reliabilitas dilakukan terhadap 30 orang mahasiswa Program Studi Gizi Poltekkes Kemenkes Pangkalpinang. Kuesioner yang telah valid dan reliabel kemudian digunakan sebagai instrument penelitian.

\section{Analisis Data}

Uji validitas penelitian dilakukan dengan menggunakan uji korelasi Product Moment Pearson. pernyataan dikatakan valid apabila $r_{\text {hitung }}$ lebih besar dibandingkan $r_{\text {tabel }}(0,361)$ dengan taraf signifikansi 95\%. Metode yang digunakan untuk mengukur reliabilitas dari alat ukur berupa kuesioner adalah metode koefisien Cronbach's Alpha. Kuesioner dikatakan reliabel jika memiliki nilai Alpha lebih besar dari 0,7.

Kuesioner yang telah diuji validitas dan reliabilitasnya kemudian digunakan dalam penelitian. Analisis kualitas pelayanan menggunakan metode SERVQUAL dilakukan melalui Langkah sebagai berikut:

1. Menetapkan CSI

Perhitungan keseluruhan CSI menurut Bhote (1996) diilustrasikan pada Tabel 1.(5)

Tabel 1. Customer Satisfaction Index (CSI)

\begin{tabular}{cccc}
\hline Pernyataan & $\begin{array}{c}\text { Ekspektasi (E) } \\
\text { Skala 1-4 }\end{array}$ & $\begin{array}{c}\text { Persepsi (P) } \\
\text { Skala 1-4 }\end{array}$ & $\begin{array}{c}\text { Skor }(\mathbf{S}) \\
(\mathbf{S})=(\mathbf{E}) \mathbf{x}(\mathbf{P})\end{array}$ \\
\hline 1 & $\ldots$ & $\ldots$ & $\ldots$ \\
$\ldots$ & $\ldots$ & $\ldots$ & $\ldots$ \\
27 & $\ldots$ & $\ldots$ & $\ldots$ \\
\hline Skor Total & Total $(\mathrm{E})=(\mathrm{Y})$ & & Total $(\mathrm{S})=(\mathrm{T})$ \\
\hline
\end{tabular}

Nilai rata-rata pada kolom E dijumlahkan sehingga diperoleh Y. Hasil kali E dan P pada kolom S dijumlahkan sehingga diperoleh T. Customer Satisfaction Index (CSI) diperoleh melalui rumus sebagai berikut:

Keterangan:

$$
\mathrm{CSI}=\frac{T}{4 Y} \times 100 \%
$$

$\mathrm{T}$ : nilai total dari CSI

4 : nilai maksimal pada skala pengukuran

Y : nilai total dari kolom Ekspektasi

Hasil perhitungan CSI dikategorikan merujuk pada KEMENPANRB (2017) seperti ditunjukkan pada Tabel 2. ${ }^{(8)}$

Tabel 2. Kategori CSI

\begin{tabular}{ccc}
\hline No & Nilai CSI $(\boldsymbol{\%})$ & Kategori \\
\hline 1 & $25,00-64,99$ & Tidak Puas \\
2 & $65,00-76,60$ & Kurang Puas \\
3 & $76,61-88,30$ & Puas \\
4 & $88,31-100,00$ & Sangat Puas \\
\hline
\end{tabular}

2. Menentukan Prioritas Perbaikan menggunakan Diagram Kartesius

Data penelitian berupa ekspektasi dan persepsi mahasiswa pada 5 dimensi SERVQUAL dikategorisasi menggunakan Diagram Kartesius yang membagi kategorisasi ke dalam 4 Kuadran, yaitu: ${ }^{(3)}$

a. Kuadran A (Prioritas Utama) 
Kategori Prioritas Utama menunjukkan elemen dengan skor ekspektasi di atas rata-rata skor keseluruhan akan tetapi skor persepsi di bawah rata-rata skor keseluruhan. Daerah ini mencerminkan kondisi mengecewakan atau tidak memuaskan.

b. Kuadran B (Pertahankan Prestasi)

Kategori Pertahankan Prestasi menunjukkan elemen dengan skor ekspektasi di atas ratarata skor keseluruhan dan skor persepsi juga berada di atas rata-rata skor keseluruhan. Daerah ini mencerminkan kondisi sangat penting dan sangat memuaskan.

c. Kuadran C (Prioritas Rendah)

Kategori Prioritas Rendah menunjukkan elemen dengan skor ekspektasi di bawah rata-rata skor keseluruhan dan skor persepsi juga di bawah rata-rata skor keseluruhan. Daerah ini mencerminkan kondisi yang kurang penting dan kurang memuaskan.

d. Kuadran D (Kemungkinan Berlebihan).

Kategori Kemungkinan Berlebihan menunjukkan elemen dengan skor ekspektasi di bawah rata-rata skor keseluruhan akan tetapi skor persepsi di atas rata-rata skor keseluruhan.

Daerah ini mencerminkan kondisi kurang penting, tetapi sangat memuaskan.

Pengukuran CSI yang dilanjutkan dengan melakukan analisis menggunakan Diagram Kartesius dapat menghasilkan hal-hal prioritas yang harus dilakukan oleh Program Studi Farmasi Poltekkes Kemenkes Pangkalpinang.

Penelitian ini telah melalui Kaji Etik dengan Keterangan Kelaikan Etik (Ethical Clearence) No. 24/EC/KEPK-PKP/XI/2018 dari Komisi Etik Penelitian Kesehatan Poltekkes Kemenkes Pangkalpinang.

\section{HASIL}

\section{Hasil Uji Validitas dan Reliabilitas}

Hasil uji validitas menunjukkan dari 30 pernyataan yang diajukan, terdapat 27 pernyataan yang valid. Pada pernyataan-pernyataan yang valid dilakukan uji reliabilitas menggunakan metode koefisien Cronbach's Alpha. Hasil uji reliabilitas menunjukkan nilai Cronbach's Alpha sebesar 0,929 (>0,700) sehingga kuesioner dinyatakan reliabel dan dapat digunakan untuk pengukuran kualitas pelayanan Program Studi Farmasi Poltekkes Kemenkes Pangkalpinang.

\section{Analisis Kualitas Pelayanan menggunakan Metode SERVQUAL}

Hasil penelitian menunjukkan kualitas pelayanan yang ditunjukkan melalui CSI sebesar 80,34\% dan berada dalam kategori Puas. Prioritas perbaikan menggunakan Diagram Kartesius dinayatakan pada Tabel 3. 
Tabel 3. Analisis Kualitas Pelayanan di Program Studi Farmasi Poltekkes Kemenkes Pangkalpinang menggunakan Metode SERVQUAL

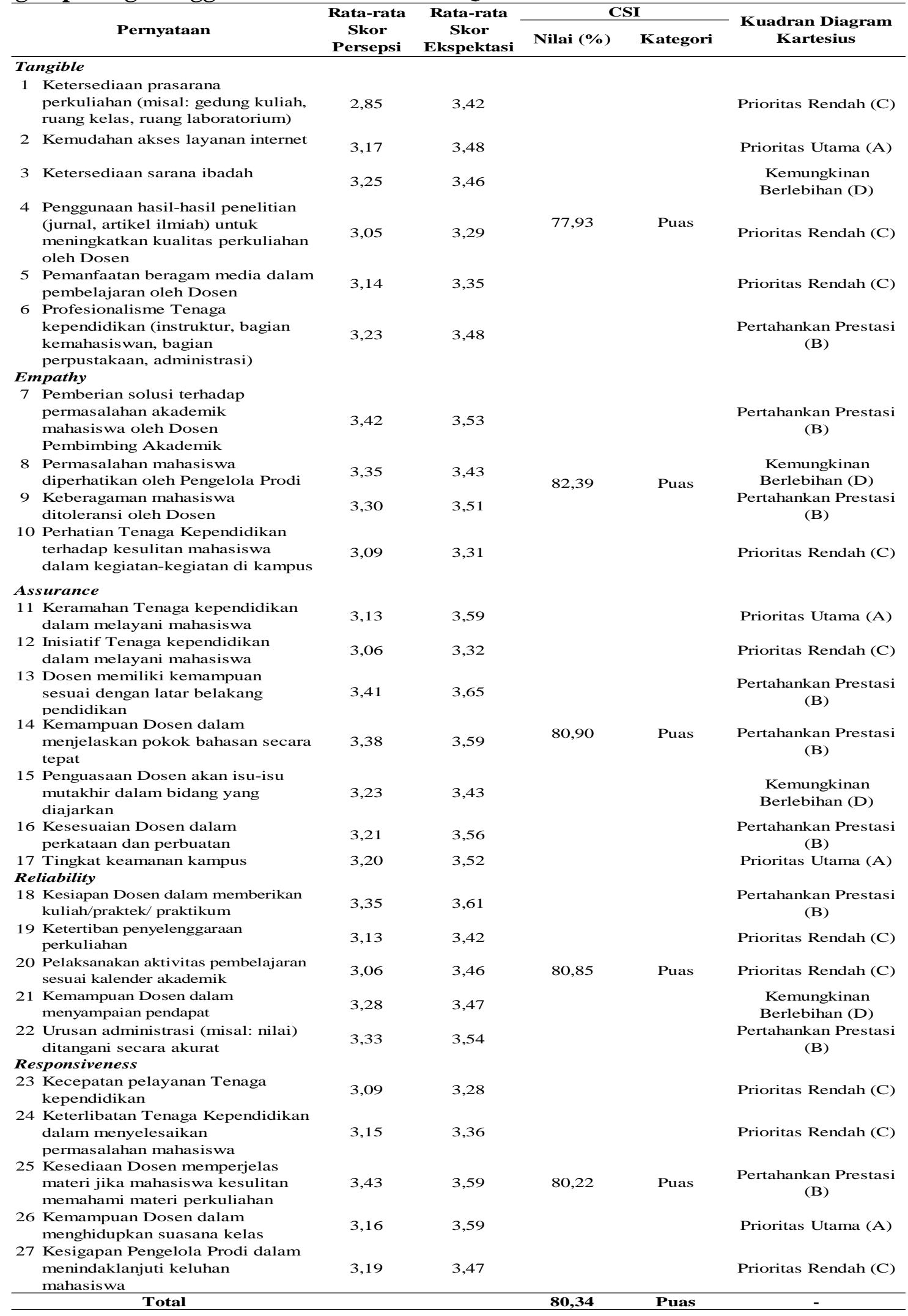




\section{PEMBAHASAN}

Pelanggan bukan hanya memberikan persepsi atau kenyataan pada pelayanan yang diterima, melainkan juga membentuk ekspektasi atau harapan. Secara umum, pelanggan membandingkan jasa anggapan (persepsi) dengan jasa yang diharapkan. Jika persepsi berada di bawah jasa yang diharapkan, pelanggan akan merasa kecewa. Pelanggan akan merasa puas bila mendapatkan pengalaman yang melebihi harapannya. ${ }^{(3)}$ Pada penelitian ini dilakukan analisis kualitas pelayanan di Program Studi Farmasi Poltekkes Kemenkes Pangkalpinang menggunakan metode SERVQUAL. Pengukuran ekspektasi dan persepsi dilakukan dengan menggunakan model kualitas jasa (SERVQUAL) pada 5 dimensi, yaitu Tangible, Empathy, Assurance, Reliability, dan Responsiveness. Pengukuran analisis kesenjangan dilakukan pada kesenjangan/gap ke-5, yaitu kesenjangan yang terjadi karena ada perbedaan antara jasa yang dirasakan dan jasa yang diharapkan. Hasil analisis berupa CSI dalam bentuk nilai (persentase) dan kategori. Selain itu hasil analisis juga berupa prioritas perbaikan serta sehingga dapat diketahui hal-hal yang harus dilakukan oleh pengelola Program Studi Farmasi Poltekkes untuk meningkatkan kualitas penyelenggaraan pendidikan. Berdasarkan hasil penetapan CSI dan penentuan prioritas perbaikan, Diagram Kartesius analisis kualitas pelayanan disajikan pada Gambar 1.

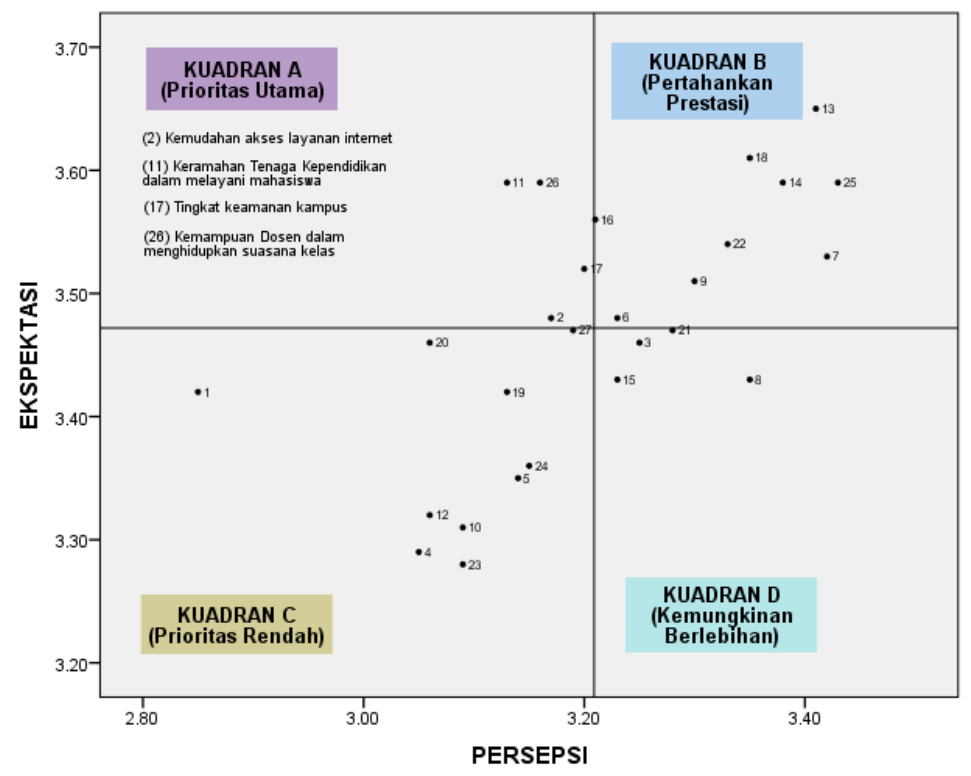

Gambar 1. Diagram Kartesius Analisis Kualitas Pelayanan di Program Studi D3 Farmasi Poltekkes Kemenkes Pangkalpinang

Keterangan:

Angka 1-27 menunjukkan pernyataan pada 5 dimensi SERVQUAL

Adapun penjelasan nilai CSI dan perioritas perbaikan pada tiap dimensi SERVQUAL sebagai berikut:

\section{Dimensi Tangible}

Dimensi tangible menunjukkan fasilitas atau bukti fisik yang diterima manfaatnya oleh mahasiswa. Secara perhitungan CSI, dimensi tangible menempati posisi indeks kepuasan terendah dibandingkan keempat dimensi SERVQUAL lainnya, yaitu sebesar 77,93\% meskipun masih dalam kategori Puas.Pada dimensi tangible, pernyataan tentang "kemudahan akses layanan internet" berada pada Kuadran A sehingga merupakan prioritas utama perbaikan. Kuadran A memperlihatkan elemen jasa penting yang tidak dilaksanakan pada tingkat yang diinginkan atau diharapkan oleh pasien. Layanan internet di kampus dan 
keberadaan hotspot/wifi merupakan hal yang perlu ditingkatkan berdasarkan pengukuran indeks kepuasan mahasiswa di Program Studi Matematika Universitas Indraprasta PGRI Jakarta. ${ }^{(9)}$ Internet dimanfaatkan oleh mahasiswa untuk menunjang proses belajar, antara lain untuk mengakses data audio, visual, audio visual pada pembelajaran; mencari berbagai informasi materi perkuliahan; mengirim data atau materi pembelajaran; mencari referensi berupa e-book, e-jurnal, dan sebagainya. ${ }^{(10)}$ Dalam memberikan pelayanan sistem informasi kepada seluruh sivitas akademika, Poltekkes Kemenkes Pangkalpinang secara terus menerus meningkatkan kapasitas bandwidth untuk mengakses internet. Poltekkes Kemenkes Pangkalpinang memiliki 12 titik Access Point (AP)/Hotspot area untuk diakses oleh 356 mahasiswa dan 10 titik Access Point (AP)/Hotspot area untuk diakses oleh pegawai dan pengelola Program Studi. Kecepatan Bandwidth setiap Access Point (AP) adalah 20Mbps, setiap AP dapat diakses oleh 30 mahasiswa sehingga jika dirata-ratakan 666,7 Kbps per mahasiswa.

Pernyataan mengenai "ketersediaan prasarana perkuliahan (misal: gedung kuliah, ruang kelas, ruang laboratorium)", "penggunaan hasil-hasil penelitian (jurnal, artikel ilmiah) untuk meningkatkan kualitas perkuliahan oleh Dosen", dan "pemanfaatan beragam media dalam pembelajaran oleh Dosen" berada pada Kuadran C yang merupakan prioritas rendah dalam perbaikan. Kategori Prioritas Rendah menunjukkan elemen dengan skor harapan di bawah rata-rata skor keseluruhan dan skor persepsi juga di bawah rata-rata skor keseluruhan. Mahasiswa sebagai pelanggan tidak menaruh harapan terlalu tinggi pada aspek tersebut dan menurut anggapan mahasiswa aspek tersebut juga tidak memiliki kinerja yang terlalu tinggi. Kualitas fasilitas kampus berpengaruh terhadap kepuasan mahasiswa. Kenaikan kualitas fasilitas kampus akan diikuti dengan meningkatnya kepuasan mahasiswa sebagai pengguna fasilitas tersebut. ${ }^{(11)}$ Hasil penelitian kepuasan mahasiswa terhadap fasilitas fisik yang ada di kampus Sekolah Tinggi Theology Jaffray Makassar sebesar 71,19\% dalam kategori Puas. ${ }^{(2)}$ Jumlah dan jenis prasarana yang tersedia di Poltekkes Kemenkes Pangkalpinang sudah mencukupi dan baik keadaannya, sehingga sangat menunjang kelancaran proses belajar mengajar. Penyediaan sarana dan prasarana merupakan bagian dari Standar Nasional Pendidikan Tinggi (SN-Dikti). ${ }^{(12)}$ Jenis prasarana yang di Poltekkes Kemenkes Pangkalpinang berupa gedung Direktorat, ruang dosen, ruang kuliah, laboratorium, perpustakaan, mushola, prasarana olahraga, kantin, dan tempat parkir. Rencana ke depan terus dikembangkan secara berkelanjutan dalam lima tahun mendatang yang didasarkan pada master plan sesuai usulan masing-masing program studi. ${ }^{(13)}$

Penggunaan hasil penelitian dan pemanfaatan beragam media dalam pembelajaran oleh Dosen menjadi prioritas perbaikan setelah prioritas utama dilakukan. Penggunaan hasil penelitian dalam proses pembelajaran merupakan bagian dari Kompetensi Profesional Dosen dan konsekwensi dari rangkaian kegiatan Tri Dharma Perguruan Tinggi yang menjadi tupoksi Dosen. ${ }^{(14)}$ Keterkaitan antara Dharma Pendidikan, Penelitian, dan Pengabmas menjadi hal yang harus diperhatikan oleh Dosen. Terkait dengan pemanfaatan beragam media dalam pembelajaran, Dosen harus dapat memanfaatkan baik media cetak maupun elektonika seperti jurnal, majalah, buku, internet, e-book, dan lain-lain. Pemanfaatan media dan teknologi pembelajaran merupakan bagian dari Kompetensi Pedagogik yang harus dimiliki oleh Dosen. Sebuah penelitian di Fakultas Ekonomi Universitas Islam "45" Bekasi menyatakan bahwa mahasiswa masih belum puas karena masih ada Dosen yang belum memanfaatkan media dan teknologi pembelajaran yang sesuai/tepat. ${ }^{(14)}$ Poltekkes Kemenkes Pangkalpinang telah mewajibkan penggunaan e-learning minimal 5\% (1 kali pertemuan) dari total pertemuan setiap mata kuliah. Penggunaan e-learning sejak Tahun Akademik 2018/2019 difasilitasi menggunakan laman http://vilep-pusdik.kemkes.go.id/poltekkespangkalpinang. 
Pernyataan mengenai "Profesionalisme Tenaga kependidikan" berada pada Kuadran B (Pertahankan Prestasi) dan "ketersediaan sarana ibadah" berada pada Kuadran D (Kemungkinan Berlebihan). Kedua kuadran ini merupakan kuadran dengan anggapan/persepsi kinerja sangat baik. Prioritas perbaikan terutama pada elemen di Kuadran A dan C perlu mendapat perhatian agar kepuasan mahasiswa selaku pelanggan semakin meningkat.

\section{Dimensi Empathy}

Dimensi empathy menunjukkan perhatian yang tulus yang diberikan kepada pelanggan.(4) Dimensi empathy merupakan dimensi dengan nilai CSI tertinggi dibandingkan keempat dimensi lainnya yaitu sebesar 82,39\% dan berada dalam kategori Puas. Meskipun demikian, peningkatan kinerja pada beberapa elemen pernyataan perlu diperhatikan untuk meningkatkan indeks kepuasan mahasiswa. Terdapat 1 pernyataan pada dimensi empathy yang berada pada Kuadran C (Prioritas Rendah) yaitu tentang "perhatian Tenaga Kependidikan terhadap kesulitan mahasiswa dalam kegiatan-kegiatan di kampus". Daerah ini mencerminkan kondisi meskipun kurang memuaskan akan tetapi juga dianggap kurang penting oleh mahasiswa. Tenaga kependidikan yang dimaksud yaitu instruktur, bagian kemahasiswan, bagian perpustakaan, dan administrasi. Studi kasus Perguruan Tinggi di Kabupaten Garut terhadap mahasiswa menyatakan kemampuan pegawai dalam memahami dan membantu mahasiswa ketika mengalami kesulitan dalam bidang akademik memiliki nilai tertinggi dalam dimensi empathy. ${ }^{(15)}$ Hal tersebut hendaknya menjadi perhatian bagi Tenaga Kependidikan di Program Studi Farmasi Poltekkes Kemenkes Pangkalpinang.

Pernyataan tentang "pemberian solusi terhadap permasalahan akademik mahasiswa oleh Dosen Pembimbing Akademik" dan "keberagaman mahasiswa ditoleransi oleh Dosen" berada pada Kuadran B (Pertahankan Prestasi). Program Studi Farmasi memberikan kesempatan kepada mahasiswa untuk berkonsultasi atas masalah-masalah yang dialami khususnya masalah akademik atau dapat pula masalah non akademik. Dosen pembimbing akademik wajib melakukan pembimbingan minimal 4 kali dalam satu semester. ${ }^{(16)}$ Pada pelaksanaannya, Dosen Program Studi Farmasi melakukan pembimbingan akademik rata-rata 4 kali dalam satu semester. Adapun ernyataan tentang "permasalahan mahasiswa diperhatikan oleh Pengelola Prodi" berada pada Kuadran D (Kemungkinan Berlebihan). Program Studi Farmasi Poltekkes Kemenkes Pangkalpinang harus mempertahankan kinerja pada elemen Kuadran B agar tetap memberikan pelayanan yang baik kepada mahasiswa. Pada Kuadran D, apabila dalam pelaksanaan elemen tersebut memerlukan sumber daya yang berlebih, maka Program Studi dapat mengurangi penggunaan sumber daya tersebut, akan tetapi jika tidak memerlukan sumber daya yang berlebih maka pelaksanaan elemen tersebut diharapkan tetap dilaksanakan dengan baik.

\section{Dimensi Assurance}

Dimensi assurance menunjukkan pengetahuan dan kesopansantunan pegawai, dalam hal ini adalah dosen dan tenaga kependidikan Program Studi Farmasi. Nilai CSI pada dimensi assurance sebesar 80,90\% dan berada pada kategori Puas. Hasil dari analisis menggunakan Diagram Kartesius menunjukkan pada dimensi assurance terdapat 2 pernyataan yang menempati Kuadran A (Prioritas Utama). Kedua pernyataan tersebut adalah "keramahan Tenaga Kependidikan dalam melayani mahasiswa" dan "tingkat keamanan kampus". Salah satu persyaratan pokok agar layanan dapat memuaskan orang atau sekelompok orang yang dilayani adalah keramahtamahan. ${ }^{(17)}$ Pernyataan pada Kuadran C (Prioritas Rendah) adalah tentang "Inisiatif Tenaga Kependidikan dalam melayani mahasiswa". Pelatihan mengenai service excellent dapat menjadi rencana kegiatan yang mendukung peningkatan kinerja Tenaga Kependidikan pada dimensi assurance. Keamanan dan kenyamanan kampus merupakan bagian dari elemen kepuasan mahasiswa. Keamanan dan kenyamanan diartikan sebagai menyediakan lampu penerangan yang memadai, mencakup dan menerangi semua area 
parkir dan area masuk; menyediakan lingkungan yang menjamin keamanan kondisi mahasiswa dan barang-barang yang dibawa selama beraktivitas di kampus; memastikan bahwa lingkungan internal sejalan dengan semua peraturan kesehatan dan keselamatan. ${ }^{(18)}$ Poltekkes Kemenkes Pangkalpinang memiliki 8 orang tenaga keamanan yang berjaga secara bergantian selama 24 jam untuk memastikan keamanan lingkungan kampus. Area parkir dibangun secara terintegrasi untuk melindungi keamanan kendaraan mahasiswa menindaklanjuti hasil Laporan Pengukuran Kepuasan Mahasiswa Tahun 2018/2019. ${ }^{(19)}$ Hal yang perlu diperbaiki jika ingin meningkatkan kepuasan mahasiswa adalah penyediaan lampu penerangan yang memadai mengingat area kampus relatif jauh dari lingkungan perkantoran lain dan perumahan penduduk.

Adapun kinerja yang telah dinilai baik oleh mahasiswa adalah tentang "Dosen memiliki kemampuan sesuai dengan latar belakang pendidikan"; "kesesuaian Dosen dalam perkataan dan perbuatan" yang merupakan indikator Kompetensi Kepribadian; "kemampuan Dosen dalam menjelaskan pokok bahasan secara tepat" dan "penguasaan Dosen akan isu-isu mutakhir dalam bidang yang diajarkan" yang merupakan indikator Kompetensi Profesional. ${ }^{(14)}$ Keempat hal tersebut berada pada Kuadran B dan D.

\section{Dimensi Reliability}

Dimensi reliability (keandalan) yaitu kemampuan untuk memberikan pelayanan sesuai dengan yang telah dijanjikan. Nilai CSI pada dimensi reliability sebesar $80,85 \%$ dan berada pada kategori Puas. Pernyataan tentang "ketertiban penyelenggaraan perkuliahan" dan "pelaksanakan aktivitas pembelajaran sesuai kalender akademik" berada pada Kuadran C (Prioritas Rendah). Perkuliahan dilaksanakan sesuai dengan jadwal yang ditentukan oleh koordinator Akademik Program Studi. Apabila terdapat Dosen yang tidak dapat menghadiri perkuliahan sesuai jadwal maka proses penggantian jadwal harus menyertakan Berita Acara Penggantian Jadwal dengan sepengetahuan koordinator Akademik Program Studi. Pelaksanakan aktivitas pembelajaran juga dijalankan sesuai dengan kalender akademik. Poltekkes Kemenkes Pangkalpinang memiliki Standar Proses Pembelajaran dan disertai dengan SOP terkait pelaksanaan pembelajaran. Audit Mutu Internal (AMI) dilaksanakan oleh tim Auditor dari Pusat Penjaminan Mutu dan Pengembangan Pendidikan di setiap akhir semester sebagai evaluasi bagi proses pembelajaran. ${ }^{(20)}$

Pernyataan tentang "kesiapan Dosen dalam memberikan kuliah/praktek/ praktikum" dan "urusan administrasi (misal: nilai) ditangani secara akurat" dinilai sebagai kondisi sangat penting dan memiliki kinerja yang sangat memuaskan (berada pada Kuadran B). Program Studi Farmasi Poltekkes Kemenkes Pangkalpinang harus mempertahankan kinerja pada elemen Kuadran B agar tetap memberikan pelayanan yang baik kepada mahasiswa. Pernyataan tentang "kemampuan Dosen dalam menyampaian pendapat" dinilai sebagai kondisi kurang penting tetapi memiliki kinerja sangat memuaskan. Pelaksanaan elemen tersebut diharapkan tetap dilaksanakan dengan baik.

\section{Dimensi Responsiveness}

Dimensi responsiveness (daya tanggap) yaitu keinginan untuk membantu para pelanggan dan memberikan pelayanan sebaik mungkin. Pelanggan dalam hal ini adalah mahasiswa Program Studi Farmasi Poltekkes Kemenkes Pangkalpinang. Nilai CSI pada dimensi responsiveness sebesar $80,22 \%$ dan berada pada kategori Puas. Pada dimensi responsiveness, pernyataan yang masuk dalam Prioritas Utama adalah tentang "kemampuan Dosen dalam menghidupkan suasana kelas". Hal tersebut sejalan dengan penelitian yang menyatakan bahwa kesenjangan terbesar antara ekspektasi dan persepsi mahasiswa pada yaitu pada kemampuan Dosen dalam menghidupkan suasana kelas. Kemampuan tersebut merupakan salah satu indikator Kompetensi Pedagogik Dosen. ${ }^{(14)}$ Seluruh dosen di Program Studi Farmasi Poltekkes Kemenkes Pangkalpinang telah mengikuti Program Peningkatan Keterampilan Teknik 
Instruksional (PEKERTI). Belmawa DIKTI menyatakan bahwa PEKERTI untuk dosen muda dan program Applied Approach (AA) untuk dosen yang lebih senior merupakan pelatihan yang dapat dimanfaatkan dalam rangka peningkatan kompetensi dosen dalam memangku jabatan fungsionalnya. Jurusan Farmasi Poltekkes Kemenkes Pangkalpinang perlu mengikutsertakan dosen-dosennya pada program AA.

Kecepatan pelayanan Tenaga kependidikan, Keterlibatan Tenaga Kependidikan dalam menyelesaikan permasalahan mahasiswa, Kesigapan Pengelola Prodi dalam menindaklanjuti keluhan mahasiswa berada pada Kuadran C (Prioritas Rendah). Kesiapan tenaga kependidikan untuk merespon setiap permintaan mahasiswa dapat menjadi tolak ukur kompetensi yang dimiliki tenaga kependidikan dan mempermudah proses berjalannya kegiatan belajar dan kebutuhan akademik mahasiswa tersebut. Tingkat kesesuaian persepsi dengan ekpektasi pada kecepatan respon Tenaga Kependidikan di pada studi kasus mahasiswa Program Studi Manajemen Universitas Buana Perjuangan Karawang sebesar 77,52\%.(21) Kesediaan Dosen memperjelas materi jika mahasiswa kesulitan memahami materi perkuliahan dinilai sebagai kondisi sangat penting dan memiliki kinerja yang sangat memuaskan (berada pada Kuadran B). Program Studi Farmasi Poltekkes Kemenkes Pangkalpinang harus mempertahankan kinerja pada elemen tersebut agar tetap memberikan pelayanan sesuai ekspektasi mahasiswa.

\section{SIMPULAN}

Kualitas pelayanan yang ditunjukkan melalui CSI sebesar $80,34 \%$ dan berada dalam kategori Puas. Prioritas utama dalam perbaikan penyelenggaraan pendidikan berdasarkan Diagram Kartesius adalah kemudahan akses layanan internet (dimensi Tangible), keramahan Tenaga Kependidikan dalam melayani mahasiswa dan tingkat keamanan kampus (dimensi Assurance) dan kemampuan Dosen dalam menghidupkan suasana kelas (dimensi Responsiveness).

\section{SARAN}

Merealisasikan rencana aksi dalam Renstra Poltekkes Kemenkes Pangkalpinang Tahun 20172021 tentang peningkatan akses layanan internet, mengadakan pelatihan Applied Aproach (AA) bagi dosen dan Service Excellent baik bagi dosen maupun tenaga kependidikan dan penelitian lanjutan mengenai analisis kualitas pelayanan untuk seluruh program studi di lingkungan Poltekkes Kemenkes Pangkalpinang.

\section{UCAPAN TERIMA KASIH}

Ucapan terimakasih ditujukan kepada Poltekkes Kemenkes Pangkalpinang sebagai pemberi dana penelitian.

\section{DAFTAR PUSTAKA}

1. Riyadi A. Total Quality Mangement in Education (Manajemen Mutu Pendidikan). Yogyakarta: IRSiSod; 2007.

2. Boky Y. Analisis Tingkat Kepuasan Mahasiswa terhadap Pelayanan Akademik Sekolah Tinggi Theologia Jaffray Makassar. J Jaffray. 2016;14(2):269-290.

3. Kotler P, Keller KL. Manajemen Pemasaran. Jakarta: Erlangga; 2009.

4. Parasuraman AP, Zeithmal VA, Berry LL. SERVQUAL: A Multiple-Item Scale for Measuring Consumer Perceptions of Service Quality. J Retail. 1988;64(1):12-40.

5. Bhote KR. Beyond Customer Satisfaction to Customer Loyalty: The Key to Greater Profitability. New York: American Management Association; 1996.

6. Widodo SM, Sutopo J. Metode Customer Satisfaction Index (CSI) untuk Mengetahui Pola Kepuasan Pelanggan pada E-Commerce Model Business to Customer. J Inform 
Upgris. 2018;4(1):38-45.

7. Faraby BA. Analisis Ekspektasi dan Persepsi Mahasiswa terhadap Mutu Pelayanan Penyelenggaraan Pendidikan di Fakultas Farmasi UGM. Universitas Gadjah Mada Yogyakarta; 2010.

8. KEMENPANRB. Peraturan Menteri Pendayagunaan Aparatur Negara dan Reformasi Birokrasi Nomor 14 Tahun 2017 tentang Pedoman Penyusunan Survey Kepuasan Masyarakat Unit Penyelenggara Pelayanan Publik. Indonesia: Kementerian Pendayagunaan Aparatur Negara dan Reformasi Birokrasi; 2017.

9. Bhakti YB, Rahmawati EY. Indeks Kepuasan Mahasiswa terhadap Pelayanan Program Studi Matematika. Form J Ilm Pendidik MIPA. 2017;7(3):272-285.

10. Walidaini B, Arifin AMM. Pemanfaatan Internet untuk Belajar Mahasiswa. J Penelit dan Bimbing Konseling. 2018;3(1):37-49.

11. Heriyanto. Pengaruh Pelayanan dan Fasilitas terhadap Kepuasan Mahasiswa Sekolah Tinggi Agama Budha Negeri Sriwijaya Tangerang Banten. J Vijjacariya. 2017;IV(1):1-14.

12. Kemenristekdikti. Peraturan Menteri Riset Teknologi dan Pendidikan Tinggi Nomor 44 Tahun 2015 tentang Standar Nasional Pendidikan Tinggi. Indonesia: Kementerian Riset Teknologi dan Pendidikan Tinggi; 2015.

13. Poltekkes Kemenkes Pangkalpinang. Rencana Strategis Poltekkes Kemenkes Pangkalpinang Tahun 2017-2021. Pangkalpinang; 2016.

14. Sulastri T. Analisis Kepuasan Mahasiswa terhadap Dosen. J Ilm Ekon Manaj dan Kewirausahaan “Optimal.” 2016;10(2):167-184.

15. Kurnaeli, Sari ITP. Analisis Kinerja Tenaga Kependidikan Akademik terhadap Kepuasan Mahasiswa: Studi Kasus Perguruan Tinggi di Kabupaten Garut. J Wacana Ekon. 2018;17(3):39-48.

16. Poltekkes Kemenkes Pangkalpinang. Panduan Akademik Politeknik Kesehatan Kemenkes Pangkalpinang Tahun Akademik 2018/2019. Pangkalpinang; 2018.

17. Yulairmi, Putu R. Manajemen Pelayanan Umum di Indonesia. Jakarta: Bumi Aksara; 2007.

18. Sukanti. Analisis Kepuasan Mahasiswa Program Studi Pendidikan Akuntansi FISE UNY. J Pendidik Akunt Indones. 2009;VIII(1):23-34.

19. Mutu UP. Laporan Pengukuran Kepuasan Mahasiswa Poltekkes Kemenkes Pangkalpinang TA. 2018/2019. Pangkalpinang; 2019.

20. Poltekkes Kemenkes Pangkalpinang. Buku III Standar Poltekkes Kemenkes Pangkalpinang. Pangkalpinang; 2018.

21. Savitri C. Analisis Kualitas Pelayanan Tenaga Kependidikan Terhadap Kepuasan Mahasiswa Universitas Buana Perjuangan Karawang (Studi Kasus Mahasiswa Prodi Manajemen). J Manaj dan Bisnis Kreat. 2016;2(1):113-132. 